\title{
Measuring Teachers' Beliefs: A Comparison of Three Different Approaches
}

\author{
Safrudiannur ${ }^{1,2^{*}}$, Benjamin Rott ${ }^{1}$ \\ ${ }^{1}$ University of Cologne, GERMANY \\ ${ }^{2}$ Mulawarman University, INDONESIA
}

Received 29 April 2019 • Revised 31 May 2019 • Accepted 15 June 2019

\begin{abstract}
The use of Likert scale items for measuring teachers' beliefs quantitatively is criticized. In this study, two quantitative methods to measure teachers' beliefs, a Likert scale instrument as well as a new instrument employing rank-then-rate items, are each compared with a qualitative approach at obtaining beliefs, i.e. interviews along with observations. In the first comparison, teachers' responses to the Likert scale instrument seem to not fit the beliefs interpreted from the qualitative approach, particularly regarding beliefs about teaching and learning. Further analyses show that a tendency to respond according to social desirability as well as unspecific teaching contexts seem to be responsible for these inconsistencies. In the second comparison, since the rankthen-rate instrument also takes students' abilities as a teaching context into account, we observed a better fit between teachers' responses to the instrument and the qualitative approach. The results of both comparisons indicate the importance of considering teaching contexts as well as alternatives to Likert scale items because of social desirability in order to have a better prediction about teachers' beliefs.
\end{abstract}

Keywords: measuring teachers' beliefs, Likert scale, social desirability, social context, students' abilities

\section{INTRODUCTION}

Some researchers have demonstrated a relationship between teachers' beliefs and their practices (Anderson, White, \& Sullivan 2005; Safrudiannur \& Rott, 2017; see Philipp, 2007; Thompson, 1992 for an overview of this research). However, other researchers have found inconsistencies regarding this relationship (Cooney, 1985; Cross Francis, 2015; Li \& Yu, 2010; Raymond, 1997). There is a debate in the field of belief research regarding these inconsistencies. On the one hand, some researchers argue that if there are inconsistencies between beliefs and practices, there should be other factors than beliefs (such as social contexts at school) influencing teachers' practices, causing teachers to act in a way that does not fit with their beliefs (Buehl \& Beck, 2015; Ernest, 1989a; Raymond, 1997). This argument indicates beliefs are "relatively stable across contexts" (Skott, 2001, p. 6).

On the other hand, some researchers argue that what teachers believe varies by contexts (Leatham, 2006) or depends on situations (Hoyles, 1992). In other words, teachers may hold different beliefs in different contexts or situations (Schoenfeld, 2015). Thus, in a particular context, if a teacher acts in a way that differs from his/her inferred beliefs (Leatham, 2006), these beliefs might be valid for other contexts, not for the particular context. In this article, particularly on beliefs about teaching and learning, we follow the latter argument.

Considering the necessity of contexts in studying beliefs, particularly social contexts at school, the best way of studying teachers' beliefs is doing qualitative research, especially intensive case studies involving interviews and observations (Philipp, 2007; Thompson, 1992). However, those methods are too time-consuming for large samples of teachers.

In contrast to the arguments for qualitative research, the most common way of measuring beliefs is by using quantitative - most often self-report - instruments, because of being less time- and cost-intensive than qualitative

(C) 2020 by the authors; licensee Modestum Ltd., UK. This article is an open access article distributed under the terms and conditions of the Creative Commons Attribution License (http://creativecommons.org/licenses/by/4.0/). 凶safrudiannur.safrudiannur@uni-koeln.de (Correspondence) $₫$ benjamin.rott@uni-koeln.de 


\section{Contribution of this paper to the literature}

- The authors criticize the use of Likert scale instruments for measuring teachers' beliefs quantitatively. The tendency to respond according to social desirability as well as unspecific teaching contexts may distort teachers' responses to Likert scale items.

- The authors offer an alternative approach for measuring teachers' beliefs quantitatively. The approach uses rank-then-rate items and considers social contexts at school related to students' abilities.

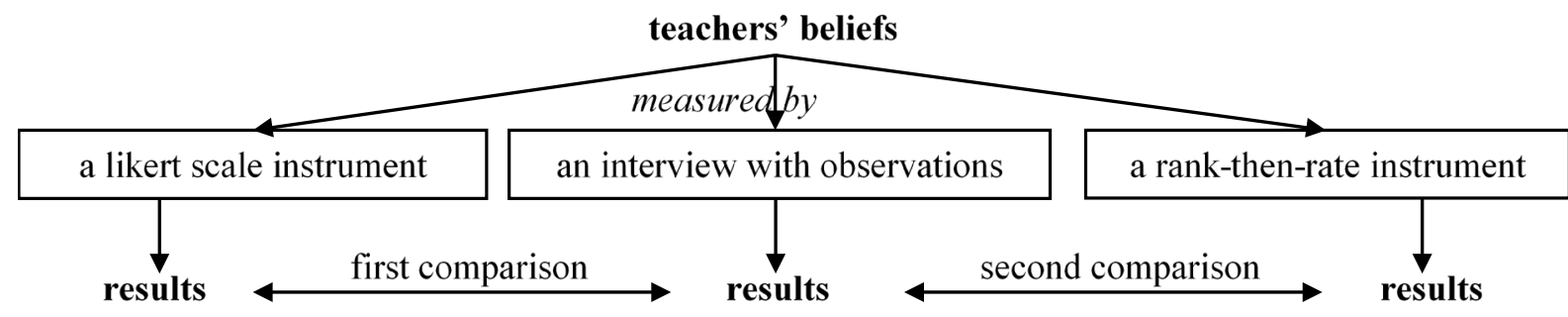

Figure 1. The framework of the study

methods. We review that most quantitative instruments employ closed items with Likert scales (e.g., Beswick, 2005; Van Zoest, Jones, \& Thornton 1994), which are easier for respondents to answer and faster for data analysis than open items (Peterson, 2000). However, the accuracy of the use of Likert scale instruments in belief research is questioned (Philipp, 2007) since Likert scale items have weaknesses: (i) they amplify social desirability (Di Martino \& Sabena, 2010) and (ii) often provide no contexts (Ambrose, Clement, Philipp, \& Chauvot, 2004).

To explore whether these two weaknesses may distort teachers' responses, we conduct this study, in which we measure teachers' beliefs by using a Likert scale instrument and an interview along with an observation. As we pointed out above, we assume that interviews and observations will provide us with more accurate results than does a Likert scale instrument.

With the motivation to provide an instrument, which can be used for large samples of teachers and may overcome some weaknesses of Likert scale items, we have developed an instrument for studying teachers' beliefs on their practice (abbreviated as TBTP) that uses rank-then-rate items and takes social contexts at school into account. In this study, we will also use the TBTP to measure teachers' beliefs and then indirectly compare the results with the results of the Likert scale instrument. So, the use of interviews along with observations is a background for the comparison of the Likert scale instrument and the TBTP. The framework of this study is presented in Figure 1. The questions are: Do the three methods lead to similar results? If the results are not similar, in which way do they differ?

\section{THEORETICAL BACKGROUND}

\section{Beliefs about the Nature of Mathematics and Beliefs about Teaching and Learning of Mathematics and Problem Solving}

There is "no consensus about an explicit definition" (Skott, 2015, p. 17) or "no agreed definition" (Beswick, 2005, p. 39) about beliefs, indicating that it is not easy to define the concept of "beliefs" (see also Furinghetti \& Pehkonen, 2002). However, we argue that it is necessary for researchers to clarify what they mean about beliefs in their studies (cf. Beswick, 2005). In this study, we refer to the definition of "beliefs" by Philipp (2007).

Philipp defines "beliefs as psychologically held understandings, premises, or propositions about the world that are thought to be true" (p. 259). Based on the definition, we argue that teachers may have various beliefs about mathematics since they may see mathematics with different views.

Ernest (1989a) subsumes beliefs about mathematics in three views and argues that teachers may combine elements from more than one of the three views:

First of all, there is the instrumentalist view that mathematics is an accumulation of facts, rules and skills to be used in the pursuance of some external end. Thus, mathematics is a set of unrelated but utilitarian rules and facts. Secondly, there is the Platonist view of mathematics as a static but unified body of certain knowledge. Mathematics is discovered, not created. Thirdly, there is the problem-solving view of mathematics as a dynamic, continually expanding 
Table 1. The relationship between beliefs about the nature of mathematics and teaching and learning of mathematics and problem solving

\begin{tabular}{lllll}
\hline The nature of & \multicolumn{2}{l}{ Teaching and learning of mathematics } & Teaching and learning of problem solving \\
\cline { 2 - 5 } mathematics & Teaching & Learning & Teaching & Learning \\
\hline Instrumentalist & $\begin{array}{l}\text { Teacher as an } \\
\text { view }\end{array}$ & $\begin{array}{l}\text { Students master skills } \\
\text { instructor }\end{array}$ & $\begin{array}{l}\text { The content- } \\
\text { correctly }\end{array}$ & $\begin{array}{l}\text { Students follow and perform the teacher's } \\
\text { methods correctly }\end{array}$ \\
\hline Platonist view & $\begin{array}{l}\text { Teacher as an } \\
\text { explainer }\end{array}$ & $\begin{array}{l}\text { Students understand } \\
\text { conceptually }\end{array}$ & $\begin{array}{l}\text { The content- } \\
\text { understanding }\end{array}$ & $\begin{array}{l}\text { Students follow and understand why the } \\
\text { teacher's methods give the correct answer }\end{array}$ \\
\hline $\begin{array}{ll}\text { Problem-solving } \\
\text { view }\end{array}$ & $\begin{array}{l}\text { Teacher as a } \\
\text { facilitator }\end{array}$ & $\begin{array}{l}\text { Students actively } \\
\text { construct knowledge }\end{array}$ & $\begin{array}{l}\text { The learner-interaction } \\
\text { (student-centered) }\end{array}$ & Students create their own strategies \\
\hline
\end{tabular}

We summarize from Ernest (1989a, p. 250-251), Van Zoest et al. (1994, p. 45-46), Beswick (2005, 40)

field of human creation and invention, a cultural product. Mathematics is a process of enquiry and coming to know, not a finished product, for its results remain open to revision. (p. 250)

Furthermore, Beswick (2005) associates the three views about mathematics by Ernest (1989a, 1989b) with the three categories about teaching and learning of mathematics and problem solving by Van Zoest et al. (1994). We summarise the association in Table 1. In this table, we consider beliefs on the same row to be consistent with each other theoretically (Beswick, 2005).

\section{Problems in Measuring Beliefs: The Weaknesses of Likert Scale Items}

As stated in the introduction, the accuracy of measuring teachers' beliefs with Likert scale items is doubted. The first weakness of Likert scale items, according to Di Martino and Sabena (2010), is that they may strengthen the tendency of teachers to answer them according to social desirability. In other words, respondents tend to answer an instrument "based on cultural norms about the desirability of certain values, traits, attitudes, interests, opinions, and behaviours" (Steenkamp, de Jong, \& Baumgartner, 2010, p. 200). Also, when respondents identify items as inherently positive, they tend to rate such items highly (McCarty \& Shrum, 1997) to "make them look good" (Paulhus, 1991, p. 17).

Responding according to social desirability may lead to unexpected results. For example, Hannula and Oksanen (2016) reported a result that was not in line with their hypotheses: Teachers' beliefs about teaching mathematics had a very small effect, even no practical significance on student affect and achievement. They assumed that this happened because teachers might elicit socially appropriate responses instead of honest responses to their Likert scale instrument.

The second weakness of Likert scale items is that they rarely provide contexts (Ambrose et al., 2004; Philipp, 2007) such as the social context at schools. Whereas, as we pointed out in the introduction, teaching contexts including social contexts at school may affect teachers' beliefs and practices (Ren \& Smith, 2018). Further, Schoenfeld (2015) also argues that teachers may elicit different beliefs in different contexts.

The results of some studies seem to support the argument. For example, Beswick (2004) interpreted Andrew, a teacher in her study, as a problem-solving/constructivist teacher based on his responses to all items in the Likert scale instrument used in her study. For instance, Andrew agreed with the item "ignoring the mathematical ideas that children generate themselves can seriously limit their learning" (ibid, p. 114). The analysis of Andrew's practice in a class of grade seven indicates the consistency with his responses reflecting the constructivist view (ibid). However, his practice in a grade ten class was different from that in the grade seven class.

Apart from brief introductions there was no whole class teaching. Rather students worked with minimal noise either individually or in twos or threes as they chose. Andrew rarely directly answered students' questions about the mathematics, but instead made suggestions. [...] In contrast with his grade ten, Andrew's grade seven lessons consisted primarily of whole class discussions facilitated and guided by Andrew. (Beswick, 2004, p. 116)

Related to the different styles of teaching, Andrew explained that the students in grade ten had less motivation than those in grade seven. Moreover, Andrew argued that the mathematics contents designed for grade ten were inappropriate for his students who had middle abilities. The case of Andrew indicates that a teacher may act differently in classes with different social contexts such as students' motivation and abilities.

Andrew's practice in his grade ten class seemed to be not in line with his response to the item "ignoring the mathematical ideas [...]" (see above). The item does not provide contexts, for example, in a class of students with high motivation/abilities or of students with low motivation/abilities. Apparently, Andrew's response to the item 
is not for a class of students with low motivation/abilities. Thus, the case of Andrew suggests the importance of considering social contexts at school for studying teachers' beliefs and practices.

Ernest (1989a) argues that social contexts at school (such as expectations of the principal of the school, of other teachers as partners in working, of students' parents but also students' behaviour or abilities) strongly influence teachers' practices and the connection between their practices with their beliefs. The case of Andrew above indicates that students' abilities may be one of the social contexts at school, which may affect his practice. Raymond (1997) also found that students' abilities as one of the immediate conditions of a classroom strongly influence teachers' actions.

Furthermore, Beswick (2018) revealed that teachers' beliefs about students' have a strong relationship with their beliefs about mathematics teaching and learning. As some researchers show, many teachers believe that solving problems, which needs higher order thinking, is only appropriate for high-achieving students (or for more able students), not for low-achieving students (e.g., Anderson et al., 2005; Zohar, Degani, \& Vaaknin, 2001).

\section{METHOD}

\section{Participants}

Participants of this study were two male Indonesian secondary teachers, Andre and Candra (pseudonyms). They are experienced teachers who have worked as math teachers for more than ten years. Furthermore, they both hold a Bachelor Degree in Mathematics Education and have participated in trainings for teachers to implement a new Indonesian curriculum for secondary school which highlights the implementation of three learning models: discovery/inquiry-based learning, project-based learning, and problem-based learning (Kementerian Pendidikan dan Kebudayaan, 2013). So, they were trained teachers. However, when we conducted this study, their schools were still implementing the old Indonesian curriculum. In contrast to the new curriculum, the old curriculum only highlights learning mathematics to solve problems (see Safrudiannur \& Rott, 2018a for the analysis of the role of problem solving in the old curriculum).

\section{Data Collection and Analysis}

In this study, we observed and recorded a lesson of each of them and then interviewed them individually (all observation and interviews were done by the first author). After more than two months, we asked them to respond to a Likert scale instrument (in this paper, we called it the LS instrument) used in Beswick (2005) as well as to the TBTP. In addition, we also asked them to respond to the RD-16 instrument for measuring the tendency for answering according to social desirability developed by Schuessler, Hittle, and Cardascia (1978). The reason for two-month delay is to minimize the influence of their interviews and observations on their responses to the LS and the TBTP.

\section{Interviews along with observations}

In the observed lesson, we asked both participants to teach mathematics as usual and to pose a problem which is compatible with the current topics in their classrooms. A few days before the lessons, we discussed with each teacher the selection of the problem (named the chosen problem) from their mathematics textbooks without discussing how to solve the chosen problem. Furthermore, we also did not discuss what they should plan and do in the observed lesson, including whether they would give students the chosen problem or their own problems.

After each lesson, we conducted a semi-structured interview to gain more information about the teacher's beliefs about teaching and learning of mathematics and problem solving. We also asked them for reasons for their actions in the observed lessons. Schoenfeld (2015) suggests that "understanding why people do (specifically, students and teachers) what they do is what really counts" (p. 397) in studying beliefs. Some example questions in the interview are:

1) What is a problem for you? What is a good problem for you? What do you think of the chosen problem?

2) How often do you involve problem solving in your lessons generally? And especially for the observed class? Why?

3) What are your criteria for a student being successful in problem solving? What do you usually do to help students successful in problem solving? Why?

4) How do you usually teach students to solve problems? Is it like what you did in the observed lesson? Why?

5) How do you teach mathematics in your classes generally and particularly in the observed class? 
Table 2. Teachers' rate to some items in the LS instrument

\begin{tabular}{|c|c|c|c|}
\hline \multicolumn{2}{|r|}{ Items in the LS instrument (Beswick 2005, p. 49-50) } & \multicolumn{2}{|c|}{ Andre Candra } \\
\hline 6. & Knowing how to solve a mathematics problem is as important as getting the correct solution. & A & SA \\
\hline 7. & Teachers of mathematics should be fascinated with how children think and intrigued by alternative ideas. & A & A \\
\hline 14. & As a result of my experience in mathematics classes, I have developed an attitude of inquiry. & A & A \\
\hline 16. & $\begin{array}{l}\text { It is the teacher 's responsibility to provide children with clear and concise solution methods for } \\
\text { mathematical problems. }\end{array}$ & D & D \\
\hline 19. & $\begin{array}{l}\text { Mathematical material is best presented in an expository style: demonstrating, explaining and describing } \\
\text { concepts and skills. }\end{array}$ & A & D \\
\hline 21. & Telling the children the answer is an efficient way of facilitating their mathematics learning. & $\mathrm{D}$ & $\mathrm{D}$ \\
\hline & $\begin{array}{l}\text { Listening carefully to the teacher explain a mathematics lesson is the most effective way to learn } \\
\text { mathematics. }\end{array}$ & D & A \\
\hline
\end{tabular}

SD: Strongly Disagree, D: Disagree, U: Undecided, A: Agree, SA: Strongly agree.

We do not present all items to save space.

6) What do you think of mathematics? (Since this is not an easy question for teachers, we also provide closed questions) Do you agree that:

a. Mathematics is a collection of facts, procedures, and formulas? Why?

b. Mathematics contents are logically interrelated and connected? Why?

c. Mathematics is still open to revision? Why?

This method to obtain espoused as well as enacted beliefs of teachers (an interview along with an observation) has previously been used by Rott (2019) with nine participants (teachers of secondary schools). Rott has shown that the method can be used to interpret teachers' beliefs reliably.

To interpret the interviews, the first author of this paper fully transcribed all interviews and then translated all transcripts into English. By using the translation, both authors independently identified keywords/statements associated with concepts of the views of mathematics from Ernest (1989a). In the independent identification, both authors had similarities and differences in interpreting the teachers' statements, but already agreed over the beliefs. Then, both authors met and discussed the differences. In the discussion, both authors reached consensus in all cases and, thus, consensually validated the interpretation of teachers' beliefs. Addressing the process of the consensual validation, Hill, Thompson, and Williams (1997) explain:

Team members first examine the data independently and then come together to present and discuss their ideas until they reach a single unified version that all team members endorse as the best representation of the data. Using several researchers provides a variety of opinions and perspectives, helps to circumvent the biases of any one person, and is helpful for capturing the complexity of the data (p. 523).

Further, by using the original transcript (to minimize translation problems), the identification and the interpretation is also done by the first author and an additional expert from Indonesia (a lecturer and researcher of the mathematics education department of a university), independently. Then, both discussed and validated the interpretations consensually. By referring to the results of the two consensual discussions, the first author made the final interpretation of teachers' beliefs.

\section{Instruments}

The Likert Scale (LS) instrument. This instrument used in Beswick $(2004,2005)$ has 26 items and uses a five-point Likert scale: strongly disagree, disagree, neutral, agree, to strongly agree. We chose this instrument because Beswick (2005) has reported the reliability and validity of the instrument and she also matches the items in the instrument with the views about the nature of mathematics from Ernest (1989a) which are also the background of this current study.

To minimise the problem with the translation from English to Bahasa Indonesia, two colleagues from the English Department of a university in Indonesia translated the instrument independently. Then, the first author discussed the translation with each of them. By using the results of the discussion, the first author made the final decision about the translation.

The Rank-Then-Rate questionnaire. All items in the LS instrument above (for example, see Table 2) can be called traditional LS items since each item only consists of one statement. A traditional LS item is one type of rate-only items (see McCarty \& Shrum, 1997), meaning that respondents only need to do a simple rating procedure to answer the item. Unlike the traditional LS item, a rank-then-rate item combines the ranking and rating procedures, requiring respondents to do ranking before rating (McCarty \& Shrum, 1997). In this paper, all rank-then-rate items 


\begin{tabular}{|c|c|c|c|c|c|c|}
\hline \multicolumn{7}{|c|}{$\begin{array}{l}\text { Item 1: When you teach the formula in a clas } \\
\text { by } \underline{\text { HA students, what is important for you? }}\end{array}$} \\
\hline \multicolumn{7}{|c|}{ RANK } \\
\hline \multirow{2}{*}{\multicolumn{7}{|c|}{$\begin{array}{l}\text { Pleas e order the three statements below by giving a rank } \\
1 \text { (the most important), 2, or } 3 \text { (the least important). } \\
\text { Statements }\end{array}$}} \\
\hline & & & & & & \\
\hline \multirow{3}{*}{\multicolumn{6}{|c|}{$\begin{array}{ll}\text { R1. } & \text { You demonstrate }[\ldots] \\
\text { R2. } & \text { You explain concepts }[\ldots] \\
\text { R3. } & \text { You let your students }[\ldots]\end{array}$}} & 3 \\
\hline & & & & & & 2 \\
\hline & & & & & & 1 \\
\hline \multicolumn{7}{|c|}{ RATE BASED ON YOUR RANK ABOVE } \\
\hline \multirow{2}{*}{\multicolumn{7}{|c|}{$\begin{array}{l}\text { Please rate the level of importance of each statement } \\
\text { based on your rank above. }\end{array}$}} \\
\hline & & & & & & \\
\hline & 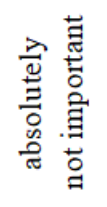 & 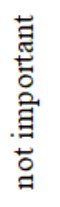 & 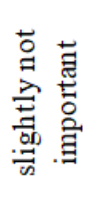 & 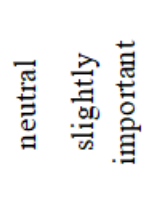 & 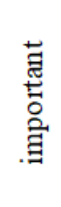 & 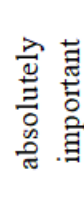 \\
\hline Statement R1 & 1 & (2) & 3 & 5 & 6 & 7 \\
\hline statement R2 & 1 & 2 & 3 & (4) & 6 & 7 \\
\hline Statement R3 & 1 & 2 & 3 & 5 & (6) & 7 \\
\hline
\end{tabular}

Item 2: When you teach the formula in a class dominated by LA students, what is important for you?

\section{RANK}

Please order the three statements below by giving a rank 1 (the most important), 2, or 3 (the least important).

\section{Statements}

R1. You demonstrate $[\ldots]$

R2. You explain concepts $[\ldots]$

R3. You let your students $[\ldots]$

\section{RATE BASED ON YOUR RANK ABOVE}

Please rate the level of importance of each statement based on your rank above.

Statements

$\underline{\text { Rate }}$

\begin{tabular}{|c|c|c|c|c|c|c|}
\hline 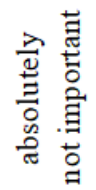 & 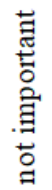 & 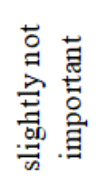 & 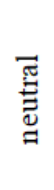 & 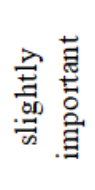 & 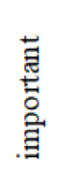 & 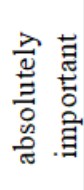 \\
\hline 1 & 2 & 3 & 4 & 5 & (6) & 7 \\
\hline 1 & 2 & 3 & 4 & (5) & 6 & \\
\hline (1) & 2 & 3 & 4 & 5 & 6 & 7 \\
\hline
\end{tabular}

- See the Appendix for the complete statements of R1, R2, and R3.

- Although we only present rating data in the appendix, the pattern of ranking data can be seen in the rating data. For example, for HA classes, Candra's rate to statement R3 of item 1 is the highest; thus, this statement has the highest (rank 1). his rate to statement R1 is the lowest, it means that statement R1 has the lowest rank (rank 3).

Figure 2. An example of Candra's responses to Item 1 and Item 2 in the TBTP

are the combination of ranking and LS questions. So, a rank-then-rate item is an alternative to using rate-only items such as traditional LS items.

We use the rank-then-rate procedure since it may reduce a participant's tendency to rate positive items highly (McCarty \& Shrum, 1997). Furthermore, McCarty and Shrum also demonstrated that rank-then-rate items increase respondents' willingness to make differentiations. As rank-then-rate questionnaires to measure mathematical beliefs did not exist prior to this study, we used the self-developed instrument called TBTP (see Safrudiannur \& Rott, 2018b).

In the TBTP, ten rank-then-rate items are grouped into three themes (see Appendix). In each item, the first, second, and third statements are always associated with the instrumentalist, the Platonist, and the problem-solving views, respectively (following the association presented in Table 1). These three statements of each item differ the TBTP (as an example, see Figure 2) from the LS instrument. As pointed out before, all items in the LS instrument are traditional LS items since each item only has one statement. Thus, respondents can rate one statement independently from other statements. In contrast, since an item in the TBTP has three statements, respondents should make a comparative judgment to the three statements at the same time before rating them to answer the item.

To answer an item in the TBTP (as an example, see Figure 2), a respondent must rank the three statements of the item before rating the three statements: firstly, a respondent orders the three statements of an item by assigning a rank 1 (the most), 2, or 3 (the least), then, s/he must rate each statement from 1 to 7 based on her/his ranks. In other words, we determined that the rate of the first rank has to be higher than that of the second rank and that of the second rank has to be higher than that of the third rank (We use this rule because if a respondent can rank two statements, s/he should have a different latent score between the two statements [Brown \& Maydeu-Olivares, 2012]). Thus, the way respondents rank the three statements influences how they rate the three statements.

This [rank-then-rate] procedure requires respondents to make choices and comparisons among values through the ranking task. With these choices and comparisons still fresh in memory, the respondents then rate the values (McCarty \& Shrum, 1997, p. 241). 


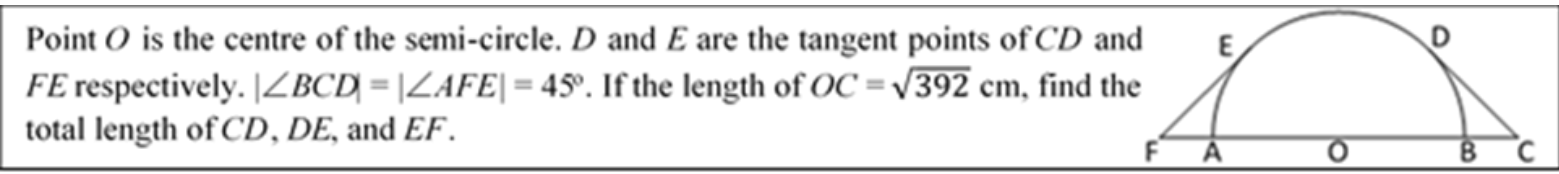

Figure 3. The chosen problem in Andre's lesson

Figure 2 presents an example of how one of the participants of this study responded to Items 1 and 2. Thus, there will be two sets of data: ranking and rating data. However, we only use rating data for analysis (as suggested by McCarty \& Shrum, 1997). The aim of the ranking part is only to psychologically force respondents to discriminate rates among statements before doing the rating. The ranking procedure (one of the forced choice format) may enhance the willingness of respondents to make a distinction between statements (Alwin \& Krosnick, 1985) and may minimize the impact of the social desirability (Paulhus, 1991, 2017).

Other than using rank-then-rate items, the TBTP is different from the LS instrument by considering students' abilities as a social context. This consideration is done by providing contexts related to students' abilities. We divided all items of Themes 1 and 2 (see Appendix) into two conditions: in a class dominated by high ability (HA) students and in a class dominated by low ability (LA) students (as an example, see Figure 2). We expect that providing these two contexts may give us insight into how teachers differentiate their beliefs about teaching and learning of mathematics and problem solving.

The terms of HA and LA students are relative terms and "used in a somewhat loose way" (Zohar et al., 2001, p. 472). Zohar et al. (2001) asked teachers to contrast high-achieving students with low-achieving students by referring to the students' performances in lessons and academic scores on tests (not standardized tests, but tests created by the teachers themselves). However, Zohar et al. (2001) use the terms achievement and ability interchangeably, for example, "the belief that achieving goals related to instruction of higher order thinking is beyond the abilities of low-achieving students" (p. 471). Thus, following the definition from Zohar et al. (2001), we define HA and LA students as mentioned in the general note of the TBTP (see Appendix).

Before this study, to ensure that teachers share a similar understanding to the definition of HA and LA students as well as to all notes and statements in the TBTP, we asked five Indonesian secondary teachers (three males, two females) to evaluate the readability and the clarity of the TBTP. Furthermore, we also discussed the TBTP with three experts to evaluate its contents (see Safrudiannur \& Rott, 2018b).

$R D-16$. The RD-16 instrument is widely used in survey studies in psychology to measure social desirability, for example, a belief study conducted by Bai, Liu, and Kou (2016). There are some instruments for measuring social desirability (see Paulhus, 1991), unfortunately, as far as we know, no instruments for measuring social desirability are developed for beliefs research in education. However, we evaluated that the RD-16 instrument is the most appropriate for our study. Besides its good validity and reliability, Schuessler et al. (1978), as well Paulhus (1991), explain that the RD-16 is suited for social studies surveying attitude-opinion, where social desirability may highly tend to take place.

Each of the RD-16 items (in total, 16 items) has two options, agree or disagree, and a key (see Schuessler et al., 1978). A respondent gets score 1 for one item if his/her answer is the same as the item's key. Thus, the maximum score is 16 with "higher score indicating more desirable responding" (Paulhus, 1991, p. 41). Our way to minimise problems with the translation for this instrument is similar to the way that for the LS instrument.

\section{RESULTS}

\section{Andre's Interview along with an Observation}

\section{The observed lesson}

The topic of Andre's lesson was tangent lines of a circle. Andre explained the topic by giving three tasks as examples whose solutions were presented in the textbook used in his class. After that, he introduced two tasks as exercises. Although students worked individually on both tasks, Andre told them to simply follow the solution methods of the previous three examples since the three examples and the two exercises were similar (only with different lengths).

After finishing the exercises, Andre posed the chosen problem (see Figure 3). His explanations and demonstrations dominated the process of solving the problem. He directed students to do what he asked (such as connecting points $\mathrm{O}$ and $\mathrm{D}$ ), reminded them of concepts (such as the properties of an isosceles right triangle) and formulas (such as the Pythagorean Theorem and the formula to calculate the length of an arc) by asking short questions, and guided them to use the formulas. 


\section{Andre's beliefs interpreted from his interview}

Related to teaching and learning of problem solving, a problem for Andre is a mathematical task which is difficult for students to solve. For him, the chosen problem is a good problem since it made students recall facts, concepts, procedures, as well as formulas from the previous topics and connect them with the current topics. Further, he expressed that a student is successful in problem solving if the student finds the correct answer. Not finding the correct answer means that students do not understand what he taught. Thus, to be successful, students need to master mathematical concepts and formulas. Therefore, it is essential for him to remind his students of mathematical concepts in solving problems (associated with the instrumentalist view). Andre's beliefs indicate the importance of recalling facts and procedures to obtain the correct answer (Thompson, 1984).

In the observed lesson, not only did he remind students of facts, concepts and formulas, but he also guided them to apply the formulas (in line with the content-performance category). He argued that most of the students had low abilities. He believes that without his guidance, the students could not solve the chosen problem.

Andre: "I need to guide them [students in the observed lesson]. If I give them a problem, they
may find, or solve the problem. But I need to give them illustrations [how to solve the
problem]. If not, they will get stuck. And then, I think, they cannot answer the problem." Interviewer: "Do you usually do what you did in the observed lesson?"

Andre: Certainly [yes]. I always guide them. I always direct them. If I let them [work alone], they can't solve the problem.

Related to teaching and learning of mathematics, Andre described his general teaching of mathematics as being like what he did in the observed lesson: when teaching mathematics, he usually starts his lessons by giving and demonstrating formulas by providing examples and then giving exercises. His teaching styles seem to reflect the role of an instructor (associated with the instrumentalist view). However, Andre critically reflected on his teaching.

Andre: “That is the weakness of my teaching. My teaching is not to find formulas. I directly give the formulas. I didn't give students [opportunities] to find the formulas. It is important, actually. By doing that, students will construct mathematical concepts by themselves."

Related to the nature of mathematics, Andre argued that mathematics consists of a collection of facts and formulas. He emphasised the importance of memorising mathematical formulas and knowing how to apply them to be successful in mathematics.

Andre: "They [students] know the formula, but they don't know the concept how to use the formula, for example, they know the Pythagorean theorem, but if they don't know its applications, it is not useful."

The expressions above seem to reflect beliefs associated with the instrumentalist view. However, he also agreed that mathematics contents are interrelated (associated with the Platonist view). Overall, our interpretation of Andre's beliefs about the nature of mathematics is dominantly associated with the instrumentalist view. We also interpreted that his beliefs about teaching and learning of mathematics and problem solving are dominantly associated with the instrumentalist view; however, these beliefs are interpreted in the context of the class for the observed lesson. Andre evaluated that many students of the class were students with low abilities in mathematics.

\section{Candra's Interview}

\section{The observed lesson}

The topic of Candra's lesson is angles formed by two parallel lines cut by a transversal (which had already been taught in the previous lessons). In the observed lesson, he posed two tasks before giving the chosen problem (see Figure 4). At the beginning of the observed lesson, he told students that he would give them problems. He motivated students to be brave to show their works in front of the class (by writing down their answers on the whiteboard of the class). 


\begin{tabular}{|c|c|c|}
\hline $\begin{array}{l}\mathrm{A} \frac{2 x / 3 x}{60} \mathrm{~B} \\
\text { a. Find } \mathrm{x} \text { ! } \\
\text { b Find }|\angle \mathrm{AOD}| \text {, and }|\angle \mathrm{BOC}| \text { ! }\end{array}$ & Find $x !$ & $\begin{array}{l}\frac{x^{\circ}}{53^{\circ}} 123^{\circ} \\
\text { Find } x !\end{array}$ \\
\hline The first task & The second task & The chosen problem \\
\hline
\end{tabular}

Figure 4. All tasks in Candra's observed lesson

Students worked on all tasks individually. However, while they worked, Candra gave his students mathematical clues. For the first task, Candra reminded them that AOB is a straight angle and thus, the size must be $180^{\circ}$. For the second task, he told his students that the total sum of all interior angles of a triangle is $180^{\circ}$ and, therefore, the total size of the three angles in the task must be $180^{\circ}$. For the chosen problem, he announced that students needed to draw an auxiliary line to be able to solve the chosen problem.

Students had opportunities to show their works regardless of having a correct answer. While the students showed their works, Candra tried to clarify what the students wrote down on the whiteboard of the class.

\section{Candra's beliefs from interview}

Regarding teaching and learning of problem solving, Candra described a problem as a difficult task for students; often students are confused how to start working on the problem. He explained that the chosen problem is a complex problem since students need to have good capability of doing basic calculations (such as addition and multiplication), doing operations in algebra, and analysing a geometrical figure to solve the problem.

Further, for him, a student is successful in problem solving, if the student has the correct answer and can explain his/her work (associated with the Platonist or problem-solving view). He also wanted his students to be brave to show and express their ideas to solve problems (associated with the problem-solving view). These beliefs reflect the learnerinteraction category which emphasises the importance of students to create their own ideas (Van Zoest et al., 1994).

However, he believes that the students in the observed teaching could not solve problems without his guidance. The students were LA students and, therefore, it is essential for him to give them mathematical clues (reflecting the instrumentalist view) and suggestions to help them (indicating the instrumentalist or Platonist views).

Candra: " $[\ldots]$ As you see how they should get guidance to solve the second task. I can't let them work alone to solve the problem. They need guidance."

He also described:

Candra: "I often did like what I did in the [observed] lesson. When students get stuck, I will give them few clues, what the key words are. Then I let them work. [...]. If they get stuck again, I will help again. So, I think, it is problem solving with guidance. Without guidance, it will be stagnant. Although there is much time, it will not be finished."

He expressed that the two tasks before the chosen problem are also clues for students. He expected that students recalled the concepts in the two tasks to solve the chosen problem. He argued that if students master the concepts, it would be not difficult for students to solve the chosen problem.

Regarding teaching and learning of mathematics, he reported that he considers students' abilities before deciding how to teach mathematics. When students in a class had good abilities, he would involve them in problem solving activities (associated with the problem-solving view). However, if he assessed that students in the class were LA students (for example, the class for the observed lesson), then the best way to teach mathematics is by explaining math topics classically, giving examples and then exercises (associated with the instrumentalist view). In his experiences, posing problems in a class with many LA students was useless and wasting time. Apparently, his beliefs about his students' abilities influence his beliefs about teaching and learning of mathematics (Beswick, 2018).

Candra: "I see the condition first [to teach math]. If students' abilities are low, then I explain a topic classically: topic, examples, and exercises. But, when I assess that the abilities are good, we can see that from their responses, when they want more tasks, I usually give them problems of which the level of difficulty increases. I will see their responses first. If they have good responses, they often ask questions, and many of them understand. But, if lots of students don't understand, I think, it is useless to increase the level of problems. It is just a waste of time." 
Regarding the nature of mathematics, Candra argued that mathematics is not a collection of facts and formulas and, therefore, he disliked students to memorise math formulas. He believes that it is possible to revise mathematical contents. He argued that a mathematical idea which is considered wrong today might be right in the future (associated with the problem-solving view). He also expressed that contents are related to each other (associated with the Platonist view) and emphasised that there should be an appropriate path connecting mathematical topics.

Overall, we interpreted Candra's beliefs about mathematics to be in between the Platonist and problem-solving views. Further, his beliefs about students' abilities seem to strongly affect his beliefs about teaching and learning of mathematics and problem solving. In different contexts of students' abilities, he seems to elicit different beliefs about teaching and learning of mathematics.

Interestingly, we noted that both teachers emphasize the effect of their students' abilities on the way they teach mathematics and problem solving. There are also other factors which might influence teachers' practices, for example, time constraints (see Candra's interview) and mathematical topics at hand. However, in our study, students' abilities seem to have a stronger effect on the teachers' practices than other factors (we need to remind readers that the social context related to students' abilities emerged from the two teachers' interviews. Our methodology in the interviews is different from that of the interviews conducted by Zohar et al. (2001) which addresses whether and how teachers differentiate their styles of teaching between high- and low-achieving students).

\section{The Correspondences between the Surveys and Interviews in Measuring Beliefs}

\section{Teachers' responses to the Likert Scale instrument}

The LS instrument consists of 26 items; according to Beswick (2005), items 1-15 (except item 4 which is associated with the Platonist view) are consistent with the problem-solving view and the learner-interaction (student-centred, see Table 1), items 16-21 are associated with either the instrumentalist or the Platonist view, and items 22-26 do not support student-centred learning (we followed the order of the items presented in Beswick, 2005, p. 49-50).

In the interview, we interpreted Andre as a teacher who holds the instrumentalist view about mathematics and mathematics teaching and learning dominantly. However, his responses to the LS instrument do not seem to reflect the instrumentalist view (inconsistent with his interview). He agreed with eleven items of items 1-15, three items of items 16-21, and only two items of items 22-26. Moreover, some of his responses (for example, to items 14, 16, and 21, see Table 2) are also inconsistent with his beliefs expressed in the interview about the best way to teach mathematics and problem solving in his class.

From the interview, we interpreted that Candra's beliefs about mathematics are in between the Platonist and problem-solving view. He agreed with twelve items of items 1-15, one item of items 16-21 and two items of items 22-26. We noted that some of his responses (for example, to items 14, 16, 19, and 21) seem to not reflect his beliefs about mathematics teaching and learning in the class for the observed lesson.

\section{Teachers' responses to the TBTP}

We present Andre's and Candra's responses to the TBTP in the Appendix. Their responses to items 1-8 indicate that they differentiate their styles of teaching between HA and LA classes. Andre's responses for LA classes seem to be consistent with his beliefs about the best way to teach his students in the observed lesson. He agreed with statements R1, S1, T1 and U1 (see Appendix), consistent with his beliefs about teaching and learning in the context of many LA students.

Similarly, Candra's rates for LA classes are consistent with his beliefs about the suitable way to teach students in the class for the observed lessson as well. His responses show that he agreed with statements R1, T1, and T2 in the context of LA classes. Interestingly, his rates for HA classes seem to reflect his intended teaching and learning of mathematics in a class with many good students.

Furthermore, both teachers' responses regarding their beliefs about mathematics (items 9 and 10) seem to be consistent with their views about mathematics interpreted from their interviews. Andre's responses to P1 and Q1 are consistent with his instrumentalist view about mathematics, and Candra's responses to P2, Q2, and Q3 are consistent with his view which is in between Platonist and problem-solving views. We summarise all results in Table 3. 
Table 3. Summary of the results of the interpretations of teachers' beliefs

\begin{tabular}{|c|c|c|c|c|}
\hline \multirow[t]{2}{*}{ Methods } & \multirow[t]{2}{*}{ The nature of math } & \multicolumn{2}{|c|}{ Teaching and learning of } & \multirow[t]{2}{*}{ Contexts } \\
\hline & & Mathematics & problem solving & \\
\hline \multicolumn{5}{|l|}{ Andre: } \\
\hline Interviews & instrumentalist view & instrumentalist view & instrumentalist view & $\begin{array}{l}\text { In a class with many LA } \\
\text { students }\end{array}$ \\
\hline The LS & $-* *$ & $\begin{array}{l}\text { problem-solving view/ } \\
\text { Platonist view }\end{array}$ & $\begin{array}{l}\text { problem-solving view/ } \\
\text { Platonist view }\end{array}$ & No context \\
\hline \multirow[t]{2}{*}{ The TBTP } & $\begin{array}{l}\text { instrumentalist view/ } \\
\text { Platonist views }\end{array}$ & $\begin{array}{l}\text { problem-solving view/ } \\
\text { Platonist view }\end{array}$ & $\begin{array}{l}\text { problem-solving view/ } \\
\text { Platonist view }\end{array}$ & HA class \\
\hline & & $\begin{array}{l}\text { instrumentalist view/ } \\
\text { Platonist view }\end{array}$ & $\begin{array}{l}\text { instrumentalist view/ } \\
\text { Platonist view }\end{array}$ & LA class \\
\hline \multicolumn{5}{|l|}{ Candra: } \\
\hline \multirow[t]{2}{*}{ Interviews } & $\begin{array}{l}\text { problem-solving view/ } \\
\text { Platonist view }\end{array}$ & problem-solving view & problem-solving view & $\begin{array}{l}\text { In a class with good } \\
\text { students* }\end{array}$ \\
\hline & & instrumentalist view & $\begin{array}{l}\text { instrumentalist view/ } \\
\text { Platonist view }\end{array}$ & $\begin{array}{l}\text { In a class with many LA } \\
\text { students }\end{array}$ \\
\hline The LS & $-* \star$ & $\begin{array}{l}\text { problem-solving view/ } \\
\text { Platonist view }\end{array}$ & $\begin{array}{l}\text { problem-solving view/ } \\
\text { Platonist view }\end{array}$ & No context \\
\hline \multirow[t]{2}{*}{ The TBTP } & $\begin{array}{l}\text { problem-solving view/ } \\
\text { Platonist view }\end{array}$ & $\begin{array}{l}\text { problem-solving view/ } \\
\text { Platonist view }\end{array}$ & $\begin{array}{l}\text { problem-solving view / } \\
\text { Platonist view }\end{array}$ & HA class \\
\hline & & $\begin{array}{l}\text { instrumentalist view/ } \\
\text { Platonist views }\end{array}$ & Platonist view & LA class \\
\hline
\end{tabular}

*"Good student" is a term used by Candra in the interview.

** We cannot infer teachers' beliefs about the nature of mathematics from the LS instrument since almost all items are about teaching and learning of mathematics and problem solving.

We need to remind readers that we consider that teachers may have a view combining more than one of the three views by Ernest. For example, Candra's responses to the TBTP about the nature of mathematics (Item 9 and item 10) indicate that his view is a combination of the Platonist and problem-solving views.

Table 4. Teachers' responses to the RD-16

\begin{tabular}{|c|c|c|c|c|c|}
\hline Items in the RD 16 (Schuessler 1978, p. 229; Paulhus 1991, p. 43) & & Andre & & Candra & \\
\hline Items & Key & Resp. & Score & Resp. & Score \\
\hline 1. I find that I can help others in many ways. & A & A & 1 & A & 1 \\
\hline 8. One can always find friends if he tries. & A & A & 1 & $\mathrm{D}$ & 0 \\
\hline 11. If the odds are against you, it is impossible to come out on top. & $\mathrm{D}$ & $\mathrm{D}$ & 1 & $\mathrm{D}$ & 1 \\
\hline 14. I often feel that no one needs me. & $\mathrm{D}$ & $\mathrm{D}$ & 1 & $\mathrm{D}$ & 1 \\
\hline Total score for all 16 items & & & 14 & & 12 \\
\hline
\end{tabular}

Resp: Responses, A: Agree, D. Disagree. Score 1 if Resp=Key, score 0 if not.

We do not present all items to save space.

\section{Teachers' responses to the $R D-16$}

We present Andre and Candra's responses to the RD-16 in Table 4. Their total scores which are close to 16 indicate that social desirability may influence their response behaviours.

\section{DISCUSSION}

In this study, we measured beliefs by using three methods, resulting in two comparisons: (1) interviews along with observations vs. the LS instrument, and (2) the interviews vs. the TBTP. From the first comparison, we found inconsistencies in responses to the LS instrument with teachers' beliefs as interpreted in the interviews, particularly the beliefs about teaching and learning of mathematics and problems solving. For example, according to our interpretation based on his expressions in the interview, Andre dominantly holds the instrumentalist view about teaching and learning. In contrast, his responses to the LS instrument do not seem to reflect these beliefs. Related to this inconsistency, we propose possible explanations.

Firstly, acting according to social desirability may have distorted Andre's responses to the LS instrument (a test for social desirability confirmed this influence for both Andre and Candra, see Table 4). For example, he agreed with a statement related to inquiry in teaching mathematics (item 14). He knew that inquiry is useful for students to construct their own understanding of mathematical concepts. However, in fact, he did not apply inquiries in his 
teaching. According to his interview, Andre emhasized that to ensure his students to be able to memorise and understand the use of mathematical formulas, he usually demonstrates and gives examples of using the formulas. This inconsistency between his responses to the LS instrument and interview indicates that what he knows about the socially desired teaching in mathematics may cause the distortion. Steenkamp et al. (2010) argue that the desirability of certain behaviours based on cultural norms may cause respondents to elicit socially desirable responses.

Another explanation regarding the inconsistencies might lie in teaching contexts. In the interviews, both Andre and Candra reported their ways of teaching in the observed classes which had many LA students. Thus, Andre's beliefs interpreted from the interview are seemingly in a context with many LA students, whereas his responses seem to reflect beliefs for another context. For example, in an LA context, it is important for him to remind students of necessary formulas and guide them step by step to ensure that they get correct answers when solving problems. In contrast, his response shows that he disagreed that a teacher should provide students with a clear and concise method to solve a problem (item 16) and tell students the method (item 21).

This explanation is also suitable for some inconsistencies between Candra's responses to the LS instrument and his beliefs from the interview. From the interview, we interpreted Candra as a teacher whose view about mathematics is in between the Platonist and problem-solving view. His responses to the Likert scale instrument about teaching and learning of mathematics and problem solving seem to be in line with the view (see Table 3). Nevertheless, the responses do not reflect the strong influence of his beliefs about students' abilities to his beliefs about teaching and learning in his class.

Candra assessed that many of his students were LA students. According to his interview, he believes that the appropriate way to teach them is by using the expository style (describing, demonstrating, and giving examples). However, in the LS instrument, he disagreed with this style (see his response to item 19). Another example, from the interview, he believes that without his guidance, his students could not solve tasks/problems. In the observed lesson, his clues for the first and second tasks are clear, concise, and precise. However, in the LS instrument, he disagreed with the responsibility of a teacher to provide a clear method to solve a problem (item 16) and tell students the method (item 21).

In the second comparison, we evaluated that the correspondence between teachers' responses to the TBTP and their interviews seems to be better than the correspondence between their responses to the LS instrument and their interviews (see Table 3). With the expectation to minimise the weakness of Likert scales for measuring beliefs, we designed the TBTP by (i) using rank-then-rate items and (ii) considering social contexts at school by providing two different contexts of students abilities. Apparently, the two teachers' responses to the TBTP satisfy our expectations. Although they tend to respond desirably, interestingly, for LA classes, they highly rated statements which are not socially desired in mathematics education like demonstrating formulas, providing many examples (R1), and emphasising the importance of giving clues in problem solving (T1). The tendency might take place in their responses to the TBTP for HA classes. For example, they highly rated the statement emphasizing the importance of discovery (R3). However, we have another explanation: the rates may be affected by their beliefs about students' abilities. For example, Candra believes that good students can solve a high level problem. Seemingly, they elicit different beliefs about teaching and learning of mathematics in different contexts of students' abilities.

\section{CONCLUSION AND LIMITATIONS}

This study has shown that teachers' beliefs interpreted from their responses to a Likert scale instrument for measuring beliefs may be inconsistent with their beliefs interpreted from interviews along with observations. Possible explanations for these inconsistencies are that Likert scale items may amplify the respondents' tendency of socially desirable responses (Di Martino \& Sabena, 2010) and often provide no contexts (Ambrose et al., 2004; Philipp, 2007).

Some researchers argue that it is not enough to interpret teachers' beliefs from the use of a Likert scale instrument and suggest the use of other methods such as interviews and observations. However, for large samples of teachers, following the suggestion is not easy. Thus, we created the TBTP. The TBTP or the method applied in the TBTP (using the rank-then-rate procedure and considering the social context related to students' abilities) can be an alternative for the use of Likert scale items to have a better prediction of teachers' beliefs, particularly for large samples. Unlike a Likert scale instrument, the TBTP allows us to investigate whether teachers have different beliefs about teaching and learning in different contexts of students' abilities as well as to analyze the interaction of teachers' beliefs and teaching contexts focussing on students' abilities statistically.

However, our study has limitations. The first limitation is the use of RD-16 to investigate whether social desirability influences teachers' responses. We evaluate that RD-16 as well as other instruments with the same intention (for example, Marlow-Crowne Scale, MMPI Lie Scale, MMPI K Scale; see Paulhus, 1991 for a review) 
assess behaviours in a general situation in daily life, not in a teaching situation. Thus, there is a need for a social desirability scale which is specifically designed for teaching behaviours.

The second limitation is the number of teachers and the number of the observed lessons of each teacher. The participants of the current study were only two teachers, and the two teachers knew that they would be observed and videotaped. Thus, they might have prepared the observed lessons well. Thus, the observed lessons might be better than their general lessons. Therefore, we also interviewed them to handle the limitation.

The third limitation is that we did not evaluate Andre's and Candra's understanding of the translated items of the LS instrument. Speer (2005) warns researchers that teachers may have a different understanding of a term in an instrument. However, we asked five teachers to evaluate all notes, questions, and statements in the TBTP to ensure that they have a similar understanding before we gave the TBTP to the two teachers in this study.

We need to also emphasize that although this case study found that there might be inconsistencies between teachers' responses to the LS instrument and their interviews based on what they did in their lessons, we cannot generalise our findings. Perhaps the inconsistencies do not happen on other teachers. However, this study has shown that the tendency of responding desirably and without providing teaching contexts may distort teachers' responses to a Likert scale instrument. Therefore, our findings suggest that researchers should be careful about the social desirability problem and teaching contexts when investigating beliefs by using a Likert scale instrument.

\section{ACKNOWLEDGEMENT}

This research is supported by Directorate General of Resources for Research, Technology and Higher Education of Indonesia (Contract number: 101.20/E4.4/2015).

\section{REFERENCES}

Alwin, D. F., \& Krosnick, J. A. (1985). The Measurement of values in surveys: A comparison of ratings and rankings. The Public Opinion Quarterly, 49(4), 535-552. https:/ / doi.org/10.1086/268949

Ambrose, R., Clement, L., Philipp, R., \& Chauvot, J. (2004). Assessing prospective elementary school teachers' beliefs about mathematics and mathematics learning: Rationale and development of a constructed-responseformat beliefs survey. School Science and Mathematics, 104(2), 56-69. https://doi.org/10.1111/j.19498594.2004.tb17983.x

Anderson, J., White, P., \& Sullivan, P. (2005). Using a schematic model to represent influences on, and relationships between, teachers' problem solving beliefs and practices. Mathematics Education Research Journal, 17(2), 9-38. https:// doi.org/10.1007/BF03217414

Bai, B., Liu, X., \& Kou, Y. (2016). Belief in a just world lowers bribery intention. Asian Journal of Social Psychology, 19, 66-75. https:// doi.org/10.1111/ajsp.12108

Beswick, K. (2004). The impact of teachers' perceptions of student characteristics on the enactment of their beliefs. In M. J. Hoines \& A. B. Fuglestad (Eds.), Proceedings of the 28th annual conference of the International Group for the Psychology of Mathematics Education (Vol. 2, pp. 111-118). Bergen: Bergen University College.

Beswick, K. (2005). The beliefs/practice connection in broadly defined contexts. Mathematics Education Research Journal, 17(2), 39-68. https:/ / doi.org/10.1007/BF03217415

Beswick, K. (2018). Systems perspectives on mathematics teachers' beliefs: Illustrations from beliefs about students. In E. Bergvist, M. Österhom, C. Granberg \& L. Sumpter (Eds.). Proceedings of the 42nd Conference of the International Group for the Psychology of Mathematics Education (Vol. 1, pp. 3-18). Umeå, Sweden: PME.

Brown, A., \& Maydeu-Olivares, A. (2012). How IRT can solve problems of ipsative data in forced-choice questionnaires. Psychological Methods, 18(1), 36-52. https:/ / doi.org/10.1037/a0030641

Buehl, M. M., \& Beck, J. S. (2015). Beliefs and teachers' practices. In H. Fives and M. G. Gill (Eds.), International Handbook of Research on Teachers' Beliefs, (pp. 66-84). New York: Routledge.

Cooney, T. J. (1985). A beginning teacher's view of problem solving. Journal for Research in Mathematics Education, 16(5), 324-336. https:/ / doi.org/10.2307/749355

Cross Francis, D. I. (2015). Dispelling the notion of inconsistencies in teachers' mathematics beliefs and practices: A 3-year case study. Journal of Mathematics Teacher Education, 18(2), 173-201. https:/ / doi.org/10.1007/s10857014-9276-5

Di Martino, P., \& Sabena, C. (2010). Teachers' beliefs: The problem of inconsistency with practice. In M. Pinto, \& T. Kawasaki (Eds.). Proceedings of the 34th Conference of the International Group for the Psychology of Mathematics Education (Vol. 2, pp. 313-320). Belo Horizonte, Brazil: PME. 
Ernest, P. (1989a). The impact of beliefs on the teaching of mathematics, in P. Ernest (Ed.), Mathematics teaching: The state of the art (pp. 249-254). London: Falmer Press.

Ernest, P. (1989b). The knowledge, beliefs and attitudes of the mathematics teacher: a model. Journal of Education for Teaching: International research and pedagogy, 15(1), 13-33. https:/ / doi.org/10.1080/0260747890150102

Furinghetti, F., \& Pehkonen, E. (2002). Rethinking characterisations of beliefs. In G. Leder, E. Pehkonen, \& G. Törner (Eds.), Beliefs: A hidden variable in mathematics education? (pp. 39-57). Dordrecht: Kluwer Academic Publishers. https://doi.org/10.1007/0-306-47958-3_3

Hannula, M., \& Oksanen, S. (2016). The effect of teacher beliefs on student affect and achievement. Paper presented at the conference of the 13th International Congress on Mathematical Education, Hamburg, Germany.

Hill, C. E., Thompson, B., \& Williams, E. N. (1997). A guide to conducting consensual qualitative research. The Counseling Psychologist, 25(4), 517-572. https:/ / doi.org/10.1177/0011000097254001

Hoyles, C. (1992). Mathematics teaching and mathematics teachers: A meta-case study. For the Learning of Mathematics, 12(3), 32-44.

Kementerian Pendidikan dan Kebudayan Indonesia. (2013). Lampiran Peraturan Menteri Pendidikan dan Kebudayaan Indonesia no. 65 tahun 2013: Standar proses untuk satuan pendidikan dasar dan menengah [The attachment of the decree of the Minister of Education and Culture of Indonesia no. 65 year 2013: The process standard for elementary and secondary school]. Retrieved on 16 November 2015 from http:/ /jdih.kemdikbud.go.id/new/public/produkhukum

Leatham, K. R. (2006). Viewing mathematics teachers' beliefs as sensible systems. Journal of Mathematics Teacher Education, 9(1), 91-102. https:/ / doi.org/10.1007/s10857-006-9006-8

Li, M., \& Yu, P. (2010). Study on the inconsistency between a pre-service teacher's mathematics education beliefs and mathematics teaching practice. Journal of Mathematics Education, 3(2), 40-57.

McCarty, J. A., \& Shrum, L. J. (1997). Measuring the importance of positive constructs: A test of alternative rating procedures. Marketing Letters, 8(2), 239-250. https:/ / doi.org/10.1023/ A:1007918705434

Paulhus, D. L. (1991). Measurement and control of response bias. In J. P. Robinson, P. R. Shaver, \& L. S. Wrightsman (Eds.), Measures of personality and social psychological attitudes (pp. 17-59). San Diego: Academic Press. https:/ / doi.org/10.1016/B978-0-12-590241-0.50006-X

Paulhus, D. L. (2017). Socially desirable responding on self-reports. In V. Zeigler-Hill, T.K. Shackelford (eds.), Encyclopedia of Personality and Individual Differences (pp. 1-5). Springer, https:/ / doi.org/10.1007/978-3-31928099-8

Peterson, R. A. (2000). Constructing effective questionnaires. Thousand Oaks: Sage Publication Inc. https:/ / doi.org/10.4135/9781483349022

Philipp, R. A. (2007). Mathematics teachers' beliefs and affect. In F. K. Lester (Ed.), Second handbook of research on mathematics teaching and learning: A project of the national council of teachers of mathematics (pp. 257-315). Charlotte, NC: Information Age Publishing.

Raymond, A. M. (1997). Inconsistency between a Beginning Elementary School Teacher's Mathematics Beliefs and Teaching Practice. Journal for Research in Mathematics Education, 28(5), 550-576. https://doi.org/10.2307/749691

Rott, B. (2019, in press). Teachers' behaviors, epistemological beliefs, and their interplay in lessons on the topic of problem solving. International Journal of Science and Mathematics Education. https:/ / doi.org/10.1007/s10763019-09993-0

Safrudiannur, \& Rott, B. (2017). Teachers' beliefs and how they correlate with teachers' practices of problem solving. In B. Kaur, W. K. Ho, T. L: Toh, B. H. \& Choy (Eds), Proceedings of the 41st Conference of the International Group for the Psychology of Mathematics Education, Vol. 4 (pp. 121-128). Singapore: PME.

Safrudiannur, \& Rott, B. (2018a). The different mathematics performances in PISA 2012 and a curricula comparison: enriching the comparison by an analysis of the role of problem solving in intended learning processes. Mathematics Education Research Journal, online first, https:/ / doi.org/10.1007/s13394-018-0248-4

Safrudiannur, \& Rott, B. (2018b). Evaluation of a questionnaire for studying teachers' beliefs on their practice (TBTP). In B. Rott, G. Törner, J. Peters-Dasdemir, A. Möller, \& Safrudiannur (Eds.), Views and Beliefs in Mathematics Education: The Role of Beliefs in the Classroom (pp. 227-238). Berlin: Springer. https:/ / doi.org/10.1007/978-3-030-01273-1_19

Schoenfeld, A. H. (2015). What counts, when? Reflection on beliefs, affect, attitude, orientations, habits of mind, grain size, time scale, context, theory, and method. In B. Pepin and B. Roesken-Winter (Eds.), From beliefs to dynamic affect systems in mathematics education (pp. 395-404). Switzerland: Springer International. 
Schuessler, K., Hittle, D., \& Cardascia, J. (1978). Measuring responding desirably with attitude-opinion items. Social Psychology, 41(3), 224-235. https:// doi.org/10.2307/3033559

Skott, J. (2001). Why belief research raises the right question but provides the wrong type of answer. Paper presented at the 3rd Nordic Conference on Mathematics Education, Kristianstad, Sweden.

Skott, J. (2015). Towards a participatory approach to 'beliefs' in mathematics education. In B. Pepin and B. RoeskenWinter (Eds.), From beliefs to dynamic affect systems in mathematics education (pp. 3-23). Switzerland: Springer International. https:/ / doi.org/10.1007/978-3-319-06808-4_1

Speer, N. M. (2005). Issues of methods and theory in the study of mathematics teachers' professed and attributed beliefs. Educational Studies in Mathematics, 58(3), 361-391. https:/ / doi.org/10.1007/s10649-005-2745-0

Steenkamp, J., de Jong, M., \& Baumgartner, H. (2010). Socially desirable response tendencies in survey research. Journal of Marketing Research, 47(2), 199-214. https:/ / doi.org/10.1509/jmkr.47.2.199

Thompson, A. G. (1984). The relationship of teachers' conceptions of mathematics and mathematics teaching to instructional practice. Educational Studies in Mathematics, 15(2), 105-127. https://doi.org/10.1007/BF00305892

Thompson, A. G. (1992). Teachers' beliefs and conceptions: A synthesis of the research. In D. A. Grouws (Ed.), Handbook of research on mathematics teaching and learning: A project of the National Council of Teachers of Mathematics (pp. 127-146). New York, NY, England: Macmillan Publishing Co, Inc.

Van Zoest, L. R., Jones, G. A., \& Thornton, C. A. (1994). Beliefs about mathematics teaching held by pre-service teachers. Mathematics Education Research Journal, 6(1), 37-55. https:/ / doi.org/10.1007/BF03217261

Zohar, A., Degani, A., \& Vaaknin, E. (2001). Teachers' beliefs about low-achieving students and higher order thinking. Teaching and Teacher Education, 17(4), 469-485. https:/ / doi.org/10.1016/S0742-051X(01)00007-5

\section{APPENDIX}

\begin{tabular}{lc}
\hline The notes, items, and statements in the TBTP & Andre Candra \\
& HA LA HA LA
\end{tabular}

General note: As a mathematics teacher, you have experience with high and low ability students

in mathematics. Consider these definitions:

A high ability (HA) student is a student who generally shows good understanding in your

lessons and regularly has high scores in your tests.

A low ability (LA) student is a student who generally does not show good understanding

in your lessons and often has low scores in your tests.

To answer all questions, you will be asked first to imagine that you have a class dominated by

HA students and then to imagine that you have a class dominated by LA students.

Theme 1: Teaching and learning of mathematics;

Note:

You are going to teach a lesson learning the formula to calculate the area of a trapezoid.

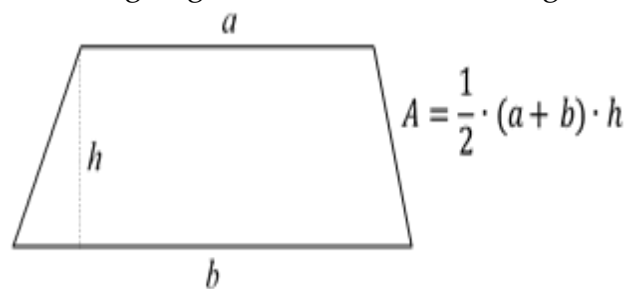

Please imagine this situation to answer items 1 to 4 .

Items 1 and 2: When you teach the formula in HA/LA classes, what is important for you?

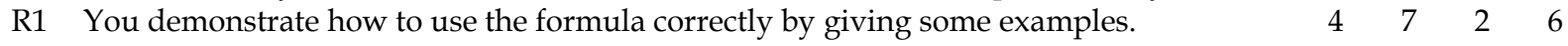

R2 You explain concepts related to how to get or to prove the formula. $\quad \begin{array}{llll}6 & 4 & 5\end{array}$

R3 You let your students discover the formulas in their own ways. $\quad \begin{array}{llll} & 7 & 4 & 6\end{array}$

Items 3 and 4: When you teach the formula in HA/LA classes, what is important for the students?

S1 They memorise and use the formula correctly.

S2 They understand the concepts underlying the formula from your explanation.

S3 They can draw logical conclusions to deduce the formula.

$\begin{array}{llll}3 & 7 & 3 & 4\end{array}$

$6 \quad 6 \quad 56$

Theme 2: Teaching and learning of problem solving;

Note: 
In problem solving, there are several definitions of a mathematical problem. Below is one of the definitions of the mathematical problem.

A mathematical problem is a task which there is no obvious or straightforward solution method to solve it.

According to the definition, a task is not a mathematical problem if it can be solved by simply applying methods taught previously. Please, see the example to understand the definition better. Example: You explained how to calculate the average of the following data: 20,16, 18, 28, 22, and

20. Then you give this following task:

The height of six basketball players is $196 \mathrm{~cm}, 200 \mathrm{~cm}, 190 \mathrm{~cm}, 185 \mathrm{~cm}, 192 \mathrm{~cm}$, and 200

$\mathrm{cm}$. Find the average height of those six players!

Although the mathematical task above is related to the real world, the task is not categorised as a mathematical problem according to the definition because your students can simply apply how to calculate the average from what you have taught. Now, have a look at the following task:

The average weight of six futsal players is $65 \mathrm{~kg}$. After substitution, the new average weight

is $63.5 \mathrm{~kg}$. If the weight of the player who left is $64 \mathrm{~kg}$, find the weight of the new player!

According to the definition, this task can be categorised as a mathematical problem because the students cannot simply apply what you have taught. Please use only this definition to answer items 5 to 8 .

Items $\mathbf{5}$ and $\mathbf{6}$ : When you pose a mathematical problem in HA/LA classes, what is important for you?

T1 You give clues about the right method or formula to solve it.

T2 Besides you assist your students, you ensure that they understand what they write.

T3 Without giving clues, you encourage your students to express their own ideas to solve it.

Items 7 and 8: When you pose a mathematical problem in HA/LA classes, what is important for the students?

U1 Through the clues you give, they recall the right method to solve it.

U2 Besides they get the correct answer with your assistance, they can explain what they write.

U3 Without your clues, they create their own strategies to solve it.

Theme 3: The nature of mathematics.

Note: Mathematics contents taught at school can be divided into several sub-domains such as numbers, algebra, geometry, measurements, statistics, and probability. The classifications of mathematics contents in general are more complex, for example, classical algebra, linear algebra, number theory, differential geometry, calculus, statistics, probability theory, etc.

Item 9: In general, what do you think of the contents of mathematics?

P1 Mathematics is an accumulation of facts, rules, and skills, which are useful for human life.

P2 The contents are interrelated and logically connected within an organisational structure.

P3 Mathematics is a dynamic process of human activities. The contents of mathematics expand and change to accommodate new developments.

$\begin{array}{llll}4 & 7 & 3 & 5 \\ 6 & 6 & 5 & 7 \\ 7 & 4 & 7 & 3\end{array}$

Item 10: What do you think of the truth of the contents of mathematics?

Q1 The truth is absolute. The contents are free of ambiguity and conflicting interpretations.

Q2 Mathematical ideas are pre-existing; humans just discover mathematics. Thus, the truthvalue of mathematics is objective, not determined by humans.

Q3 The contents are created by humans and, thus, the truth-value is also established by humans.

- Items $1=2,3=4 ; 5=6 ; 7=8$, but with a different class (questions 1,$3 ; 5 ; 7$ for a HA class and 2, 4; $6 ; 8$ for a LA class, as an example, see Figure 2). There is no differentiation for items 9 and 10.

- The rating scale for items 1-8 is from 1 (absolutely not important) to 7 (absolutely important); it for items 9 and 10 is from 1 (strongly disagree) to 7 (strongly agree). As an example, see Figure 2.

- R1, S1, T1, U1, P1, Q1 is associated with the instrumentalist view; R2, S2, T2, U2, P2, Q2 is associated with the Platonist view; R3, S3, T3, U3, P3, Q3 is associated with the problem-solving view.

The content of the TBTP presented in this appendix has been fully published in Safrudiannur and Rott (2018b).

\section{http://www.ejmste.com}

